\title{
MAPPING LAND COVER CHANGE AND MODELLING ITS IMPACTS ON THE INUNDATION RESPONSES OF THE AGUSAN MARSH, MINDANAO, PHILIPPINES
}

\author{
M. M. Makinano-Santillan 1, 2, *, J. R. Santillan ${ }^{1,2}$ \\ ${ }^{1}$ Caraga Center for Geo-Informatics, Caraga State University, Ampayon, Butuan City, 8600, Philippines \\ - (mmsantillan, jrsantillan)@ carsu.edu.ph \\ ${ }^{2}$ Department of Geodetic Engineering, College of Engineering and Geosciences Caraga State University, Ampayon, Butuan City, \\ 8600, Philippines
}

Commission III, WG III/10

KEY WORDS: Wetlands, Agusan Marsh, Land cover Change, Land cover Monitoring, Satellite Remote Sensing, Inundation Modelling

\begin{abstract}
:
Monitoring of environmental changes is one of the most popular applications of satellite remote sensing. In this study, we applied satellite remote sensing to map and monitor changes in land cover of Agusan Marsh, one of the most ecologically significant wetlands, and an important region of biodiversity in the Philippines. Multi-temporal land cover maps of the Agusan Marsh over a 22year period from 1995 to 2017 were generated through Maximum Likelihood classification of Landsat 5, TM, ETM+ and OLI images. Post-classification change detection of the land-cover maps showed that more than $60 \%$ of the marsh is naturally vegetated during the mapping period. Agricultural/cultivated areas were the second dominant land cover and were found to be increasing through the years while wetland vegetation generally showed a downward trend. Two-dimensional (2D) flood modelling using HEC RAS was also performed to estimate how the Agusan Marsh would react to extreme rainfall events in terms of depth and extent of inundations. Simulation results showed that the Agusan Marsh responded differently for each year in terms of inundation depth and extent. These results of the combined satellite remote sensing $+2 \mathrm{D}$ modelling approach implemented in this study would be essential to better understand landscape patterns in the Agusan Marsh, including changes and interactions between human activities and natural phenomenon such as flooding for proper marsh management and improved decision-making.
\end{abstract}

\section{INTRODUCTION}

The Agusan Marsh is one of the most ecologically significant wetlands, and an important region of biodiversity in the Philippines (Primavera and Tumanda Jr., 2008). It is an extensive floodplain within the Agusan River Basin (ARB) in north-eastern Mindanao, containing nearly $15 \%$ of the Philippines's freshwater resources over an area of approximately $960 \mathrm{~km}^{2}$ in size (Figure 1). It includes an exceptionally large area of swamp forest and a peat swamp forest that can only be found in this part of the country. The marsh has long been considered to acts as storage for rainwater and reduces the downstream flow of flood water into population centers situated along the Agusan River. It has also been reported to support the largest expanses left in the Philippines of seven habitat types such that a major portion of the marsh called the Agusan Marsh Wildlife Sanctuary (AMWS) has been declared as a Ramsar Site No. 1009 in 1999 not only to value its role as an internationally important wetland, but also to encourage national action and international cooperation for its conservation and sustainable use of its resources (Ramsar, 1999). With such significant and diverse roles, it is crucial to map the marsh's land cover (including those of the watersheds supplying water to the marsh) and monitor its changes over time and space. The impacts of this land cover changes to the inundation responses of the marsh during extreme rainfall events must also be understood.

The goal of this study was to generate multi-temporal land cover maps for land cover change monitoring in the Agusan
Marsh over a 22-year period from 1995 to 2017 using Landsat images. It also aims to estimate how the Agusan Marsh would react to extreme rainfall events in terms of depth and extent of inundations through two-dimensional (2D) flood modelling. This study is a continuation of the land-cover change mapping and analysis that we have conducted for the ARB (Santillan et al., 2019).

\section{METHODS}

\subsection{Multi-temporal Land-cover Mapping}

Orthorectified images acquired by Landsat 5 Thematic Mapper (TM), Landsat 7 Enhanced Thematic Mapper + (ETM+), and Landsat 8 Operational Land Imager (OLI) were downloaded from USGS Earth Explorer (https://earthexplorer.usgs.gov/) and used for land-cover mapping. The years considered include 1995, 2002, 2005, 2010, 2015 and 2017. The year 1995 was chosen as baseline for the mapping and analysis as it represents the state of the marsh prior to implementation of government laws and programs that may have either regulated or enhanced anthropogenic activities within the marsh and in areas surrounding it such as the Mining Act of 1995; AMWS declaration as protected area in 1996; and National Greening Program in 2011.

Figure 2 summarizes the steps employed in generating the landcover maps.

\footnotetext{
* Corresponding author
} 


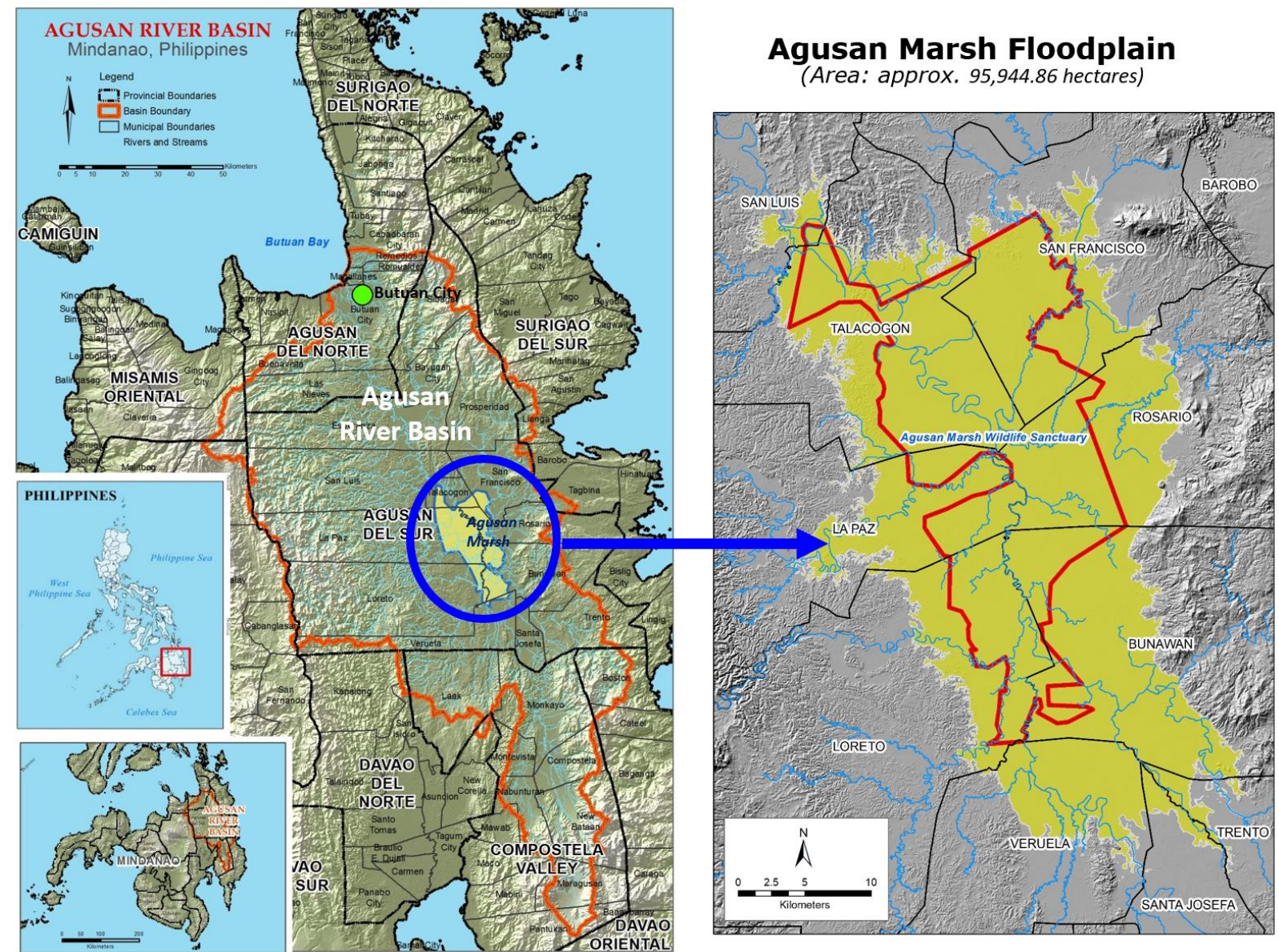

Figure 1. Location of the Agusan Marsh within the Agusan River Basin (ARB) in Mindanao, Philippines. Within the marsh floodplain is the Agusan Marsh Wildlife Sanctuary (AMWS), a protected area.

\begin{tabular}{|c|c|c|c|c|c|}
\hline $\begin{array}{l}\begin{array}{c}\text { Download of Raw } \\
\text { Landsat Image }\end{array} \\
\text { - March } 23,2017 \\
\text { - April } 24,2017 \\
\text { - April } 8,2017 \\
\text { - May } 26,2017 \\
\text { - June } 27,2017 \\
\text { - July 13, } 2017 \\
\text { - July 29, 2017 } \\
\text { - August } 30,2017\end{array}$ & $\begin{array}{l}\text { Image Pre- } \\
\text { processing } \\
\text { - Image Co- } \\
\text { registration } \\
\text { - Radiometric } \\
\text { Calibration } \\
\text { - Atmospheric } \\
\text { Correction } \\
\text { - NDVI Computation } \\
\text { - Layerstacking }\end{array}$ & $\begin{array}{l}\text { Cloud and Cloud } \\
\text { Shadow Digitizing } \\
\text { - Digitizing of Clouds } \\
\text { and Cloud Shadows }\end{array}$ & $\begin{array}{l}\text { Maximum Likelihood } \\
\text { Classification } \\
\text { - Collection of training } \\
\text { and accuracy } \\
\text { assessment ROls } \\
\text { using high resolution } \\
\text { Google Earth Images } \\
\text { - Land-cover } \\
\text { classification using } \\
\text { Maximum Likelihood } \\
\text { Classification }\end{array}$ & $\begin{array}{l}\text { Missing Data } \\
\text { Supplementation } \\
\text { - Integration of } \\
\text { classification results } \\
\text { of Main image and } \\
\text { supplemental } \\
\text { images }\end{array}$ & $\begin{array}{l}\begin{array}{c}\text { Contextual Editing } \\
\text { and Accuracy } \\
\text { Assessment }\end{array} \\
\text { - Conversion to GIS } \\
\text { shapefile } \\
\text { - Correction of very } \\
\text { obvious } \\
\text { misclassifications } \\
\text { - Accuracy } \\
\text { assessment }\end{array}$ \\
\hline
\end{tabular}

Figure 2. Location of the Agusan Marsh within the Agusan River Basin (ARB) in Mindanao, Philippines. Within the marsh floodplain is the Agusan Marsh Wildlife Sanctuary (AMWS), a protected area. 
As the marsh is located within ARB, any changes in land cover upstream would have direct effect to the marsh. It was then a necessity to perform land cover mapping for the whole ARB. The ARB is contained in two Landsat scenes (path 112, rows 54 and 55). To address the limitations brought by cloud covers, and to ensure complete land cover mapping, several images for each year were downloaded and subjected to classification.

A total of 62 images were downloaded, and all underwent radiometric calibration, and atmospheric correction using FLAASH in Envi 5 software. Normalized Vegetation Difference Index (NDVI) images were also generated and used as additional bands.

Each layerstack of surface reflectance bands and NDVI for each imagery date was independently classified using Maximum Likelihood classifier. The major land cover classes (and their sub-classes) are agricultural/cultivated lands (banana, coconut, cropland, and oil palm), barren lands (barren areas, exposed riverbeds), built-up (residential, commercial, infrastructures), forest (natural and plantation forests, shrubs, and other trees), grassland, water (sea, rivers, lakes, fishponds), and wetlands (mangrove, marshes, nipa, other submerged vegetation). At least 1000 pixels were collected for each class for classifier training; another independent set containing at least 100 pixels per class were used to assess the accuracy of each classified image in terms of producer's, user's, and overall classification accuracies.

From the land-cover maps generated for the whole ARB, the portions corresponding to Agusan Marsh flood plain with an area of approximately $95,944.86$ hectares were subjected to post-classification change detection to generate land-cover change maps and statistics.

\subsection{Inundation Modelling}

Two-dimensional (2D) flood modelling was then performed to estimate how the Agusan Marsh would react to extreme rainfall events in terms of depth and extent of inundations. For this purpose, a pure 2D flood model of the whole ARB based on Hydrologic Engineering Center River Analysis System (HECRAS) Version 5.0.7 was developed using LiDAR-derived Digital Terrain Model (DTM) as source of topographic information (Figure 3).

Different versions of the model were prepared, with each version corresponding to the land cover condition for a particular year, and the corresponding land cover map as basis for assignment of Manning's surface roughness, which is one of the major parameters of the model.
A rainfall event with a return period of 2 years (i.e., $126 \mathrm{~mm}$ of rain in 24 hours which has a $50 \%$ probability of occurrence in any given year) was used as the model's boundary condition. The inundation maps generated for each year were analysed for differences in terms of depth and extent.

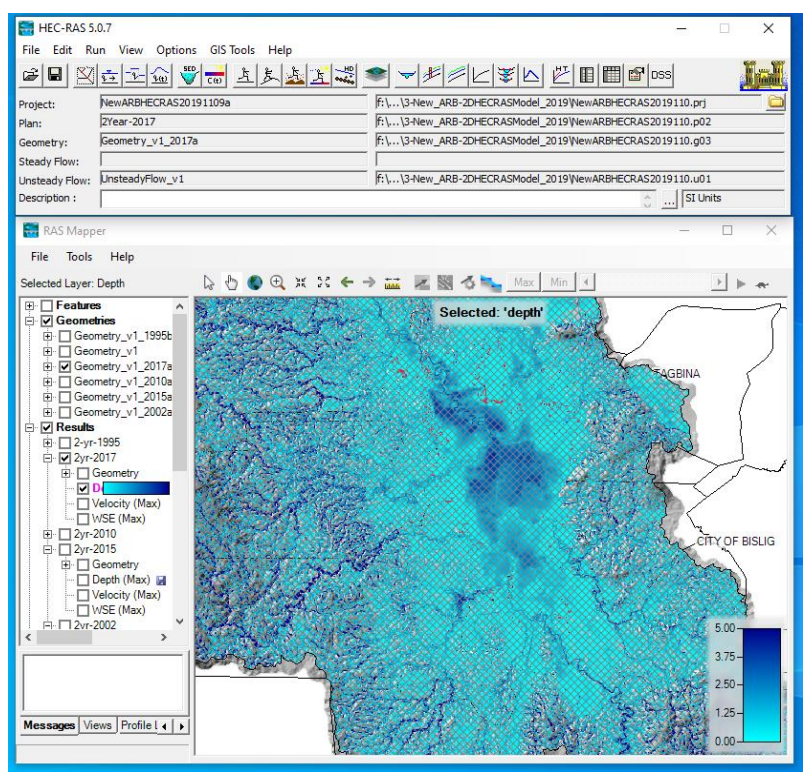

Figure 3. The two-dimensional HEC-RAS model developed for inundation analysis of the Agusan Marsh.

\section{RESULTS AND DISCUSSION}

\subsection{Land-cover and its Changes in the Agusan Marsh}

The study was able to generate 30-m resolution land-cover maps of the ARB with overall classification accuracies ranging from $90 \%$ (for the year 1995) to 96\% (for the year 2002) based on independent classification accuracy assessment. The average overall classification accuracy is $93.30 \%$.

The land-cover maps and statistics for the portion of the Agusan Marsh are shown in Figures 4 to 6.

Percentage of land cover class statistics derived from the Level 1 maps revealed that the Agusan Marsh was 68\% and 66\% naturally vegetated (wetland vegetation + forest + grassland) in 1995 and 2017, respectively. Agricultural/cultivated areas were the second dominant land cover at $21 \%$ and $28 \%$ of the marsh in 1995 and 2017, respectively. Relative to the original area of agricultural/cultivated land in 1995, an increase by $36 \%$ was found (from $199 \mathrm{~km}^{2}$ in 1995 to $271 \mathrm{~km}^{2}$ in 2017 (Figure 7). 


\section{Land Cover}

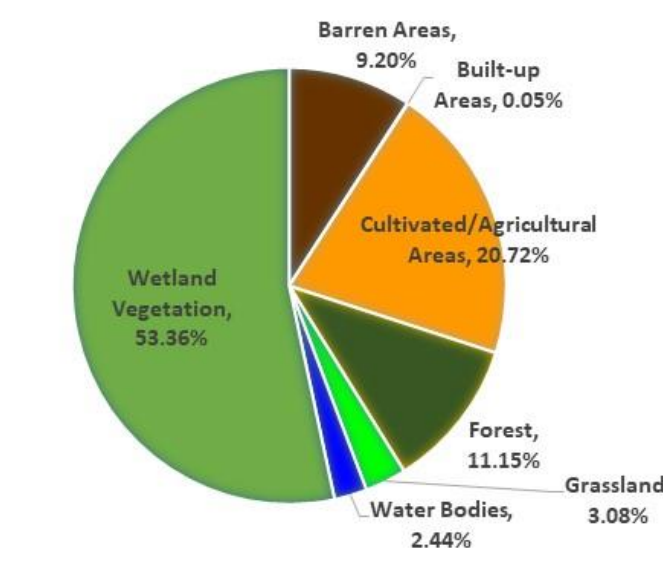

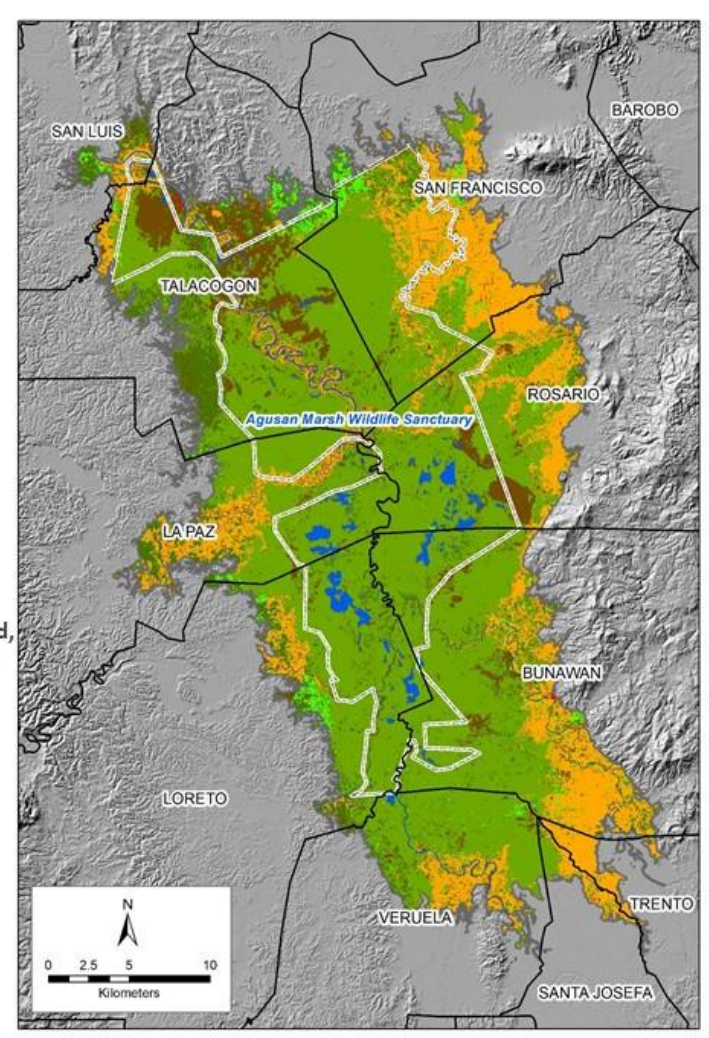

\section{Land Cover}
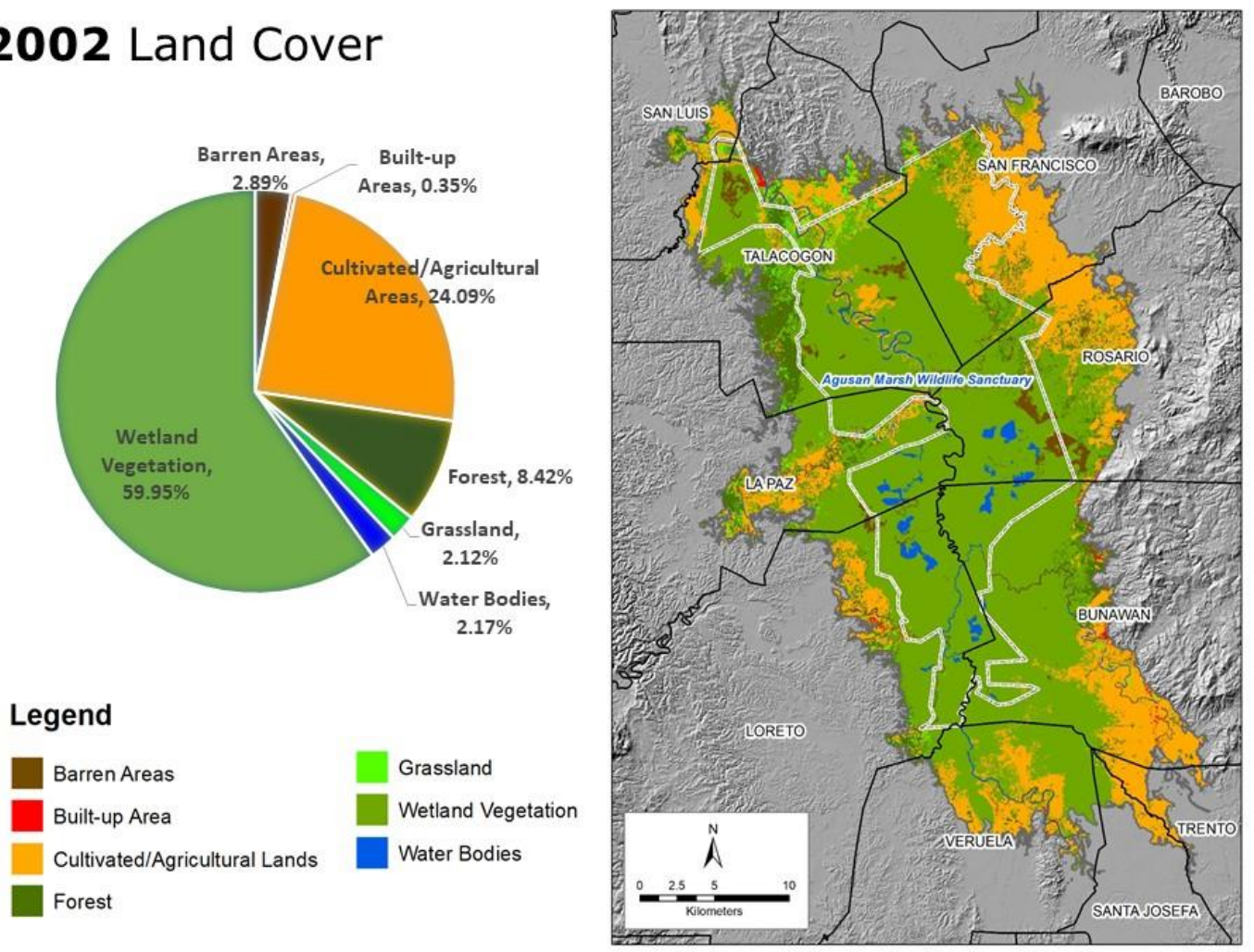

Figure 4. Land-cover maps and statistics of the Agusan Marsh derived from multi-temporal Landsat images for the years 1995 and 2002. The polygon with white outline is the Agusan Marsh Wildlife Sanctuary (AWMS). 


\section{Land Cover}

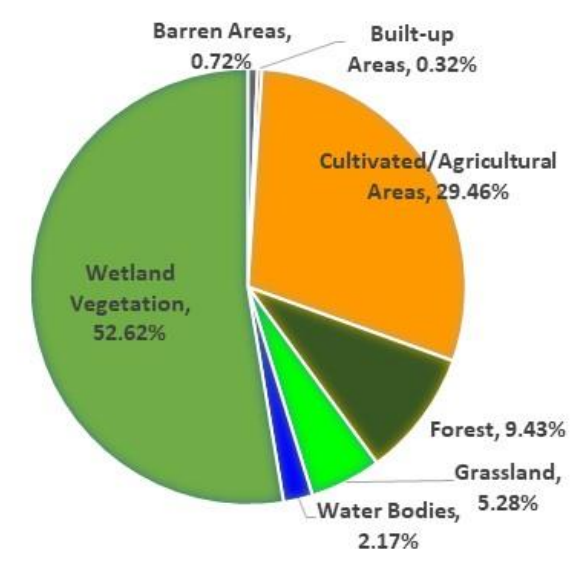

\section{Legend}

Barren Areas
Built-up Area
Cultivated/Agricultural Lands
Forest

\section{Land Cover}

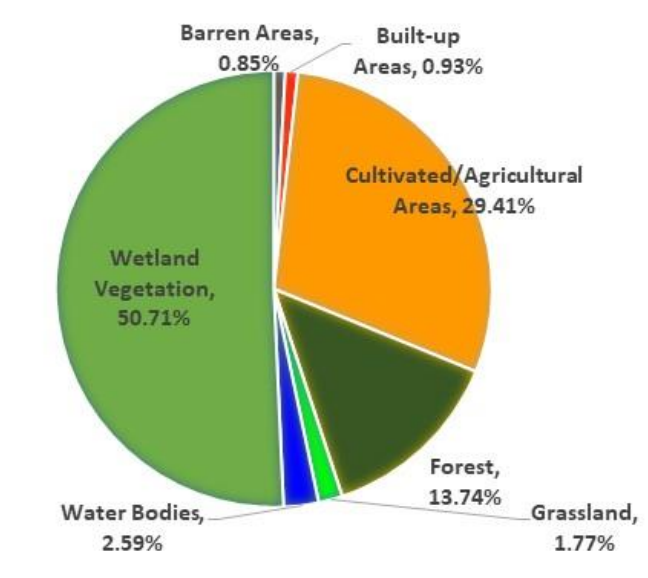

\section{Legend}

Barren Areas

Built-up Area

Cultivated/Agricultural Lands

Forest
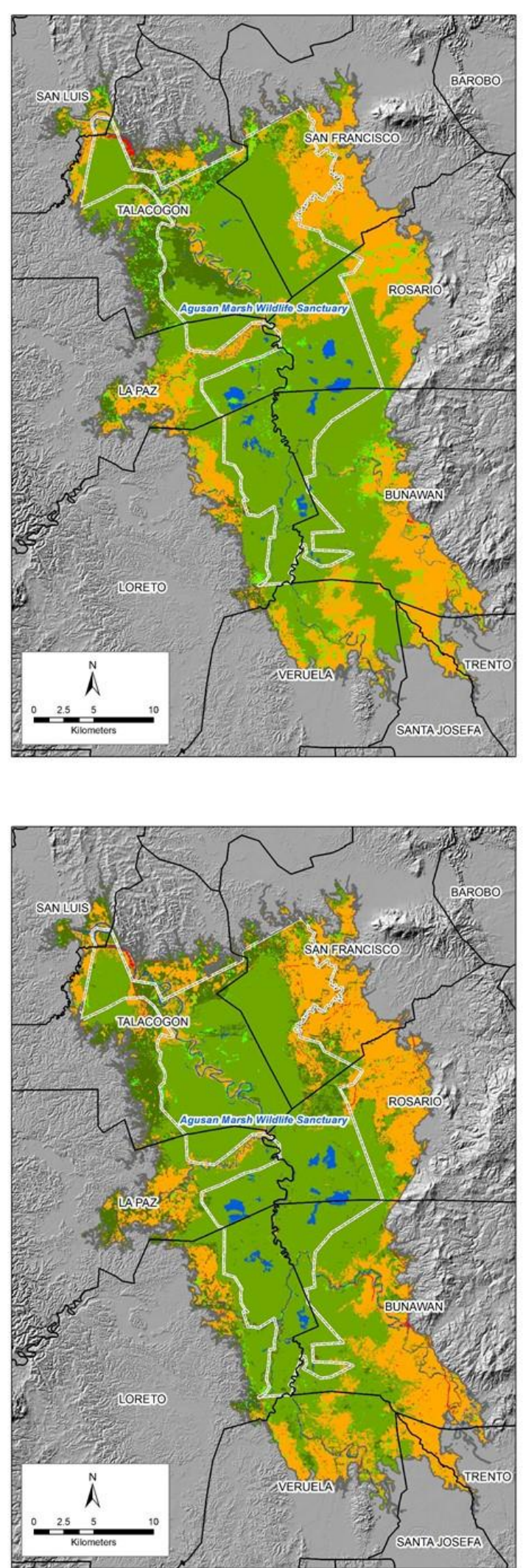

Figure 5. Land-cover maps and statistics of the Agusan Marsh derived from multi-temporal Landsat images for the years 2005 and 2010. 


\section{Land Cover}
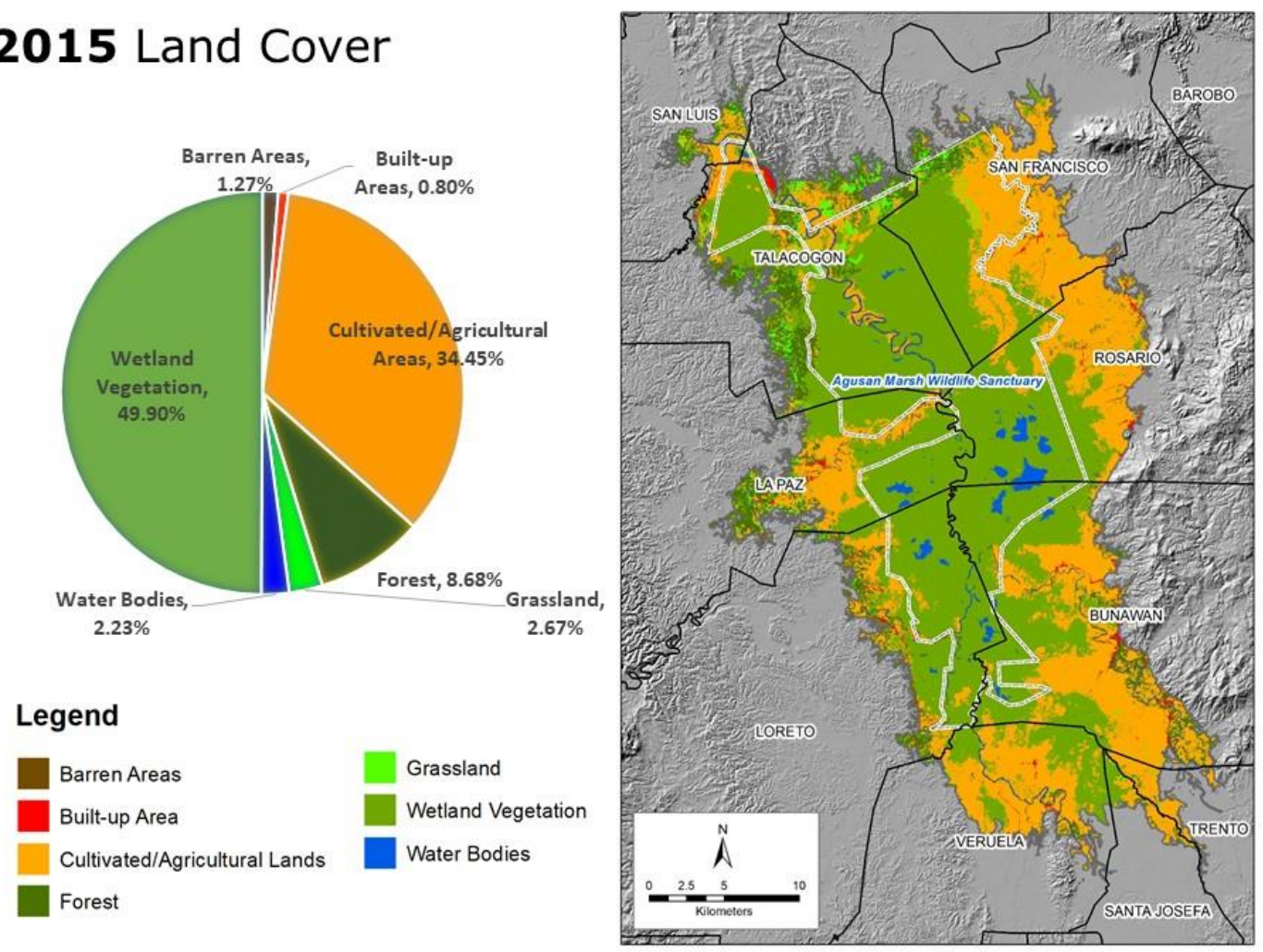

\section{Land Cover}

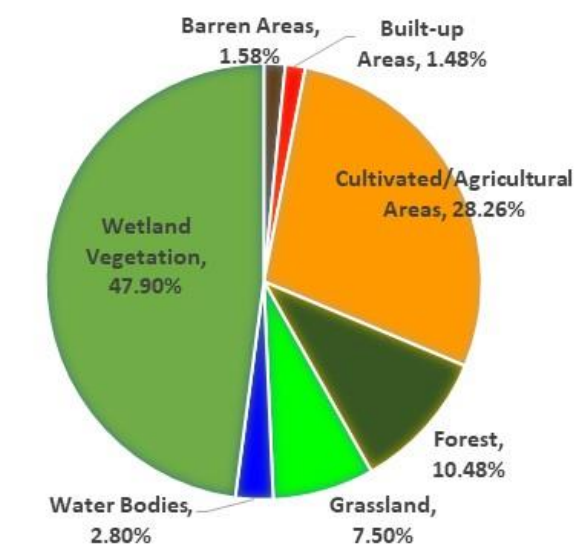

\section{Legend}
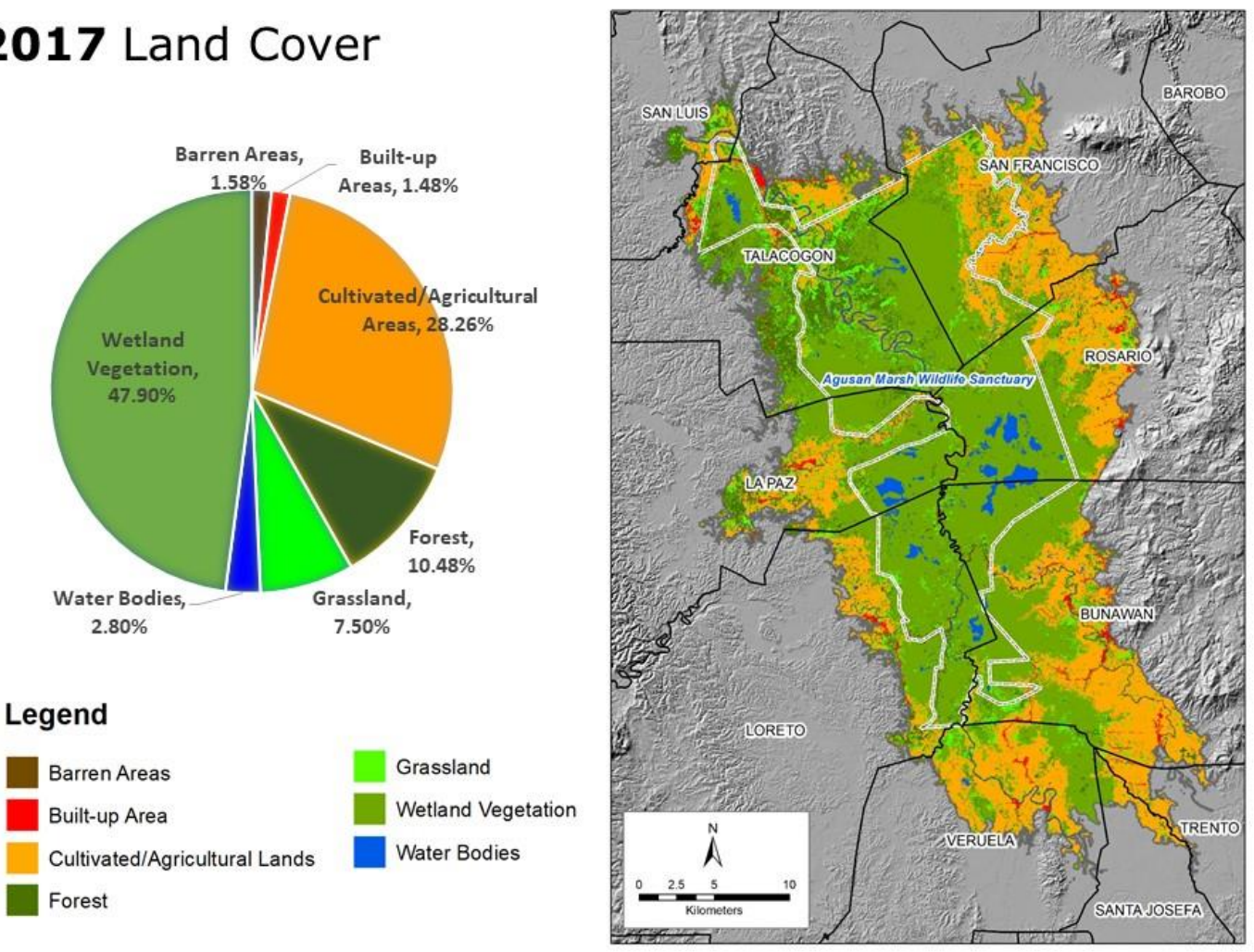

Figure 6. Land-cover maps and statistics of the Agusan Marsh derived from multi-temporal Landsat images for the years 2015 and 2017. 
It was the year 2015 that agricultural/cultivated lands were at the highest, occupying $34 \%$ of the total marsh area. It was also in that year that natural vegetation was at lowest percentage of $61 \%$. Built-up areas in the marsh were found to be small $(<1 \%)$. These results revealed that agricultural activities in the marsh are increasing through the years, confirming earlier studies that reported land-cover conversions for rice, corn, banana, and oil palm plantations (Varela et al., 2013; Gibbens, 2021).

Another significant finding is that agricultural/cultivated areas are not only increasing in extent; the direction where this expansion takes places is from the outskirt portions of the marsh towards the AMWS, a protected area. Spatial analysis further revealed that agricultural/cultivated lands have already encroached the northeast portion of the AMWS in 1995, and this encroachment has increased until 2017.

Within the AMWS, a relatively similar trend in land-cover change can also be observed (Figure 8). While this portion is considered a protected area, there was an observed increase in cultivated/agricultural areas and decrease in wetland vegetation.

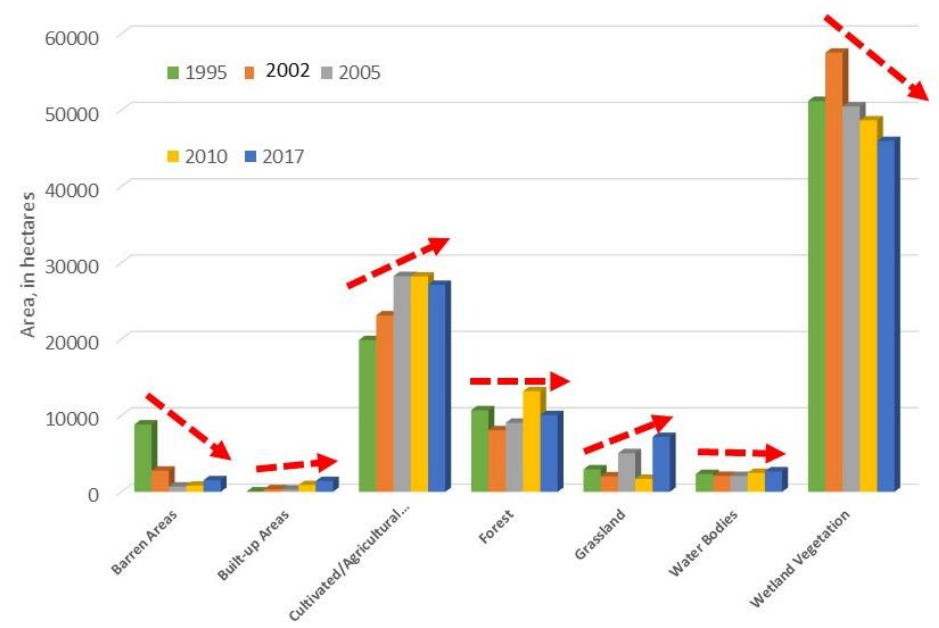

Figure 7. Overall trend of land-cover changes for the Agusan Marsh.

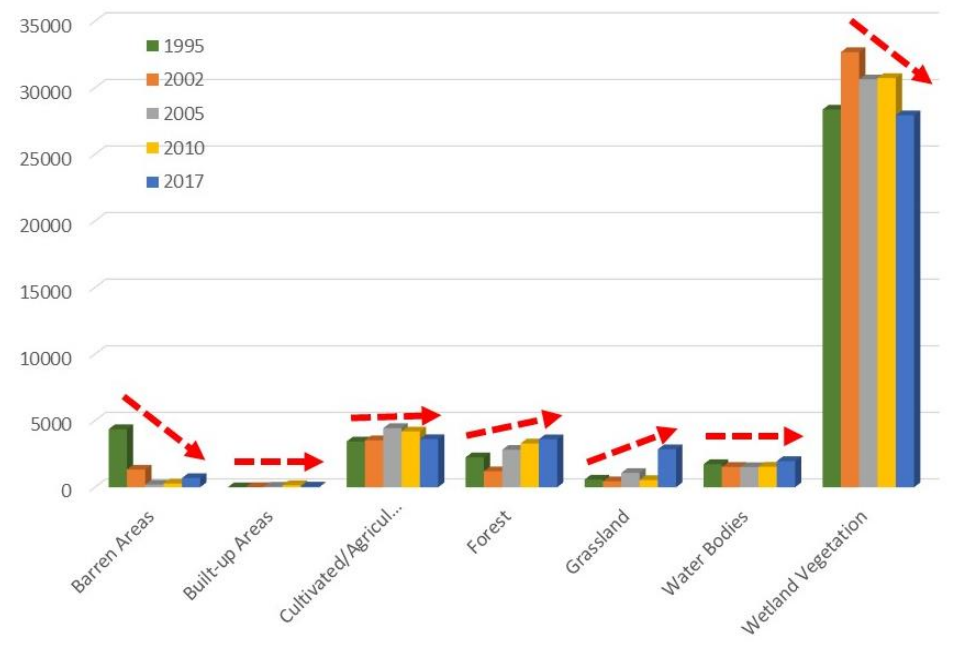

Figure 8. Overall trend of land-cover changes within the Agusan Marsh Wildlife Sanctuary, a protected area.

\subsection{Simulated Depth and Extent of Inundations in the Agusan Marsh}

Shown in Figure 9 are the results of the 2D flood modelling of the inundation and depth of extent in the portion of the Agusan Marsh for 1995 and 2017. These results simulate how the Agusan Marsh would respond to a rainfall event based on various land-cover conditions that were mapped from Landsat images.

In general, simulation results showed that the Agusan Marsh responded differently for each year in terms of inundation depth and extent, although the differences are relatively insignificant
(Figure 10). The average simulated inundation depth all over the marsh was highest at $1.21 \mathrm{~m}$ in 2017, and lowest in 2010 at 0.90 $\mathrm{m}$.

Areas within the marsh that have become inundated have the smallest extent in 2010 and 2015 (64\% inundated) and largest in 1995 and 2002 (69\% inundated). This seems to suggest that the response of the marsh to rainfall events does not change considerably from 1995 to 2017 . These modelling results may be attributed to the relatively low magnitude of changes that have occurred in the marsh based on the multi-temporal land cover maps. 

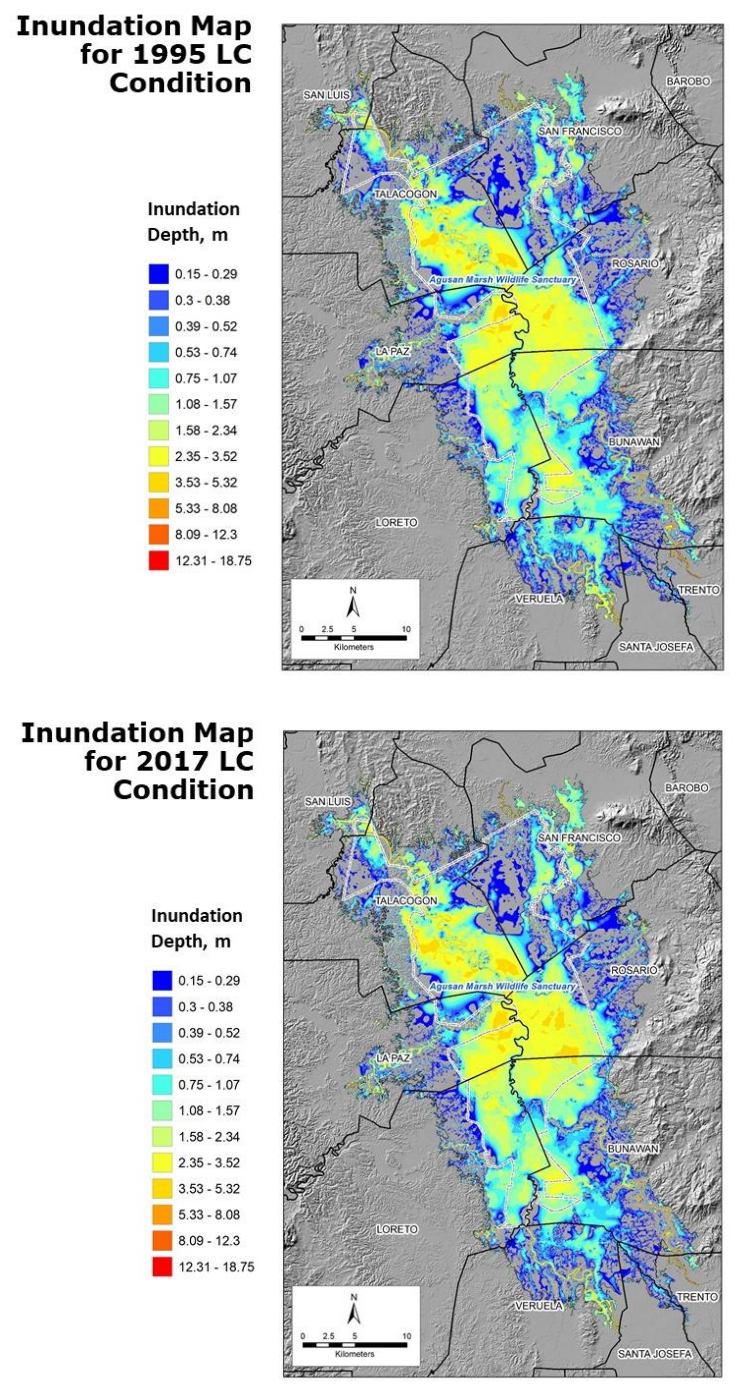

Figure 9. Example HEC-RAS model-simulated inundations (clipped for the Agusan Marsh portion) according to different land cover (LC) conditions (1995 and 2017).

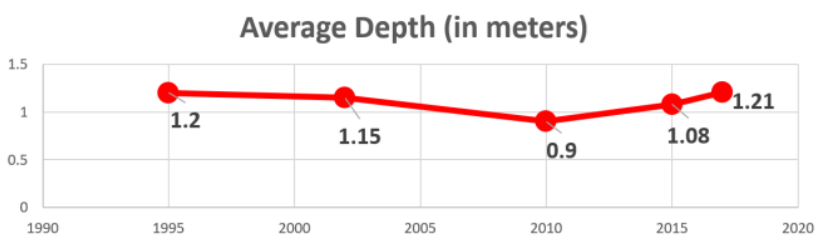

Inundated Area (in hectares)

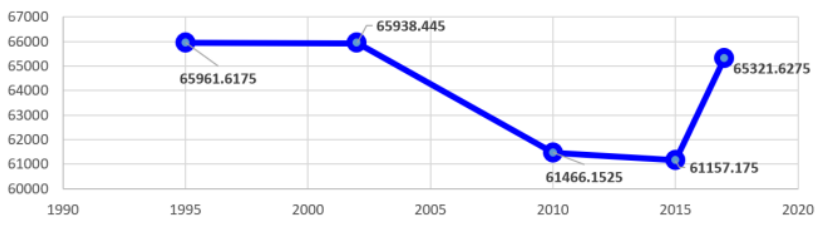

Figure 10. Summary of 2D flood modelling simulation result for the Agusan Marsh under different years/land-cover conditions.

\section{CONCLUSIONS}

In this study, multi-temporal land cover maps of the Agusan Marsh over a 22-year period from 1995 to 2017 through
Maximum Likelihood classification of Landsat 5, TM, ETM+ and OLI images. Post-classification change detection of the land-cover maps showed that more than $60 \%$ of the marsh is naturally vegetated during the mapping period. Agricultural/cultivate areas were the second dominant land cover and were found to be increasing through the years while wetland vegetation generally showed a downward trend. Twodimensional (2D) flood modelling using HEC RAS was then performed to estimate how the Agusan Marsh would react to extreme rainfall events in terms of depth and extent of inundations. Simulation results showed that the Agusan Marsh responded differently for each year in terms of inundation depth and extent.

To our knowledge, these satellite remote sensing and modelling-based findings are first to be reported by the study. The results would be essential to better understand landscape patterns in the Agusan Marsh, including changes and interactions between human activities and natural phenomenon such as flooding for proper marsh management and improved decision-making.

\section{ACKNOWLEDGEMENTS}

This work is an output of the Geo-SAFER Agusan Project, one of the component projects of the Geo-SAFER Mindanao Program (Geo-informatics for the Systematic Assessment of Flood Effects and Risks towards a Resilient Mindanao), a research program supported and funded by the Philippine Council for Industry, Energy and Emerging Technology Research and Development (PCIEERD) of the Department of Science and Technology (DOST), Philippines. We would like to acknowledge Engr. Monalaine Bermoy, Engr. Joy Casinginan, and Engr. Janice Baay for their assistance in image processing, cloud and shadow digitization, and image classifications.

\section{REFERENCES}

Primavera, J. H. and Tumanda Jr., M. I., 2008. The Agusan Marsh: A situationer with focus on scientific aspects. In: Proceedings of the 1st Scientific Conference on the Agusan Marsh, Butuan City, Agusan del Norte, Philippines, 5-14.

Gibbens, S., 2021. The world's wetlands are slipping away. This vibrant sanctuary underscores the stakes. National Geographic,

https://www.nationalgeographic.com/environment/article/world -wetlands-are-slipping-away-agusan-marsh-underscores-stakes (April 26, 2021).

Ramsar, 1999. Agusan Marsh Wildlife Sanctuary, Ramsar Sites Information Service, https://rsis.ramsar.org/ris/1009.

Santillan, J.R., Amora, A.M., Makinano-Santillan, M., Gingo, A.L., Marqueso, J.T., 2019. Analyzing the impacts of land cover change to the hydrologic and hydraulic behaviours of the Philippines' third largest river basin. ISPRS Annals of Photogrammetry, Remote Sensing \& Spatial Information Sciences, IV-3/W1, 41-48. doi.org/10.5194/isprs-annals-IV-3W1-41-2019.

Varela, R., Fernandez, E. and Degamo, J., 2013. Agricultural development and habitat change in the Agusan River Basin in Mindanao, Philippines. International Journal of Development and Sustainability, 2(3), 2020-2030. 